\title{
DEVELOPMENTAL ASSETS AND SEXUAL AND REPRODUCTIVE HEALTH AMONG 10- TO 14-YEAR-OLDS IN NORTHERN UGANDA
}

\author{
Peter C. Scales, Maura Shramko, and Kim Ashburn
}

\begin{abstract}
There is a need for research on adolescent sexual and reproductive health (SRH) to further clarify the broader developmental context of very young adolescents who are generally neglected in SRH research in developing countries. Programs can then address these factors: (including quality of family, school, and peer relationships, commitment to learning, and various social competencies), thereby broadening valid intervention targets and increasing program effectiveness among vulnerable youth. In this study, cross-sectional survey data measured the extent of developmental assets (youths' individual strengths and social relationships and opportunities) and concurrent SRH outcomes among a stratified random sample of 941 very young adolescents (10 to14 years old) in northern Uganda. We hypothesized that youth with higher levels of assets would have better SRH. Mean developmental assets level was barely adequate. However, as predicted, youths with higher levels of the assets were more likely to have accurate HIV knowledge, accurate condom knowledge, the ability to access SRH services, supportive relationships in which SRH issues can be discussed, and were more likely to have the intention of delaying sexual intercourse or using condoms. The asset-SRH health linkage was stronger for girls than for boys. The findings suggest a potential utility for promoting individual and social assets, such as positive relationships and opportunities, commitments to learning, and social competencies, as a strategy for promoting SRH among very young adolescents in a developing country setting.
\end{abstract}

Keywords: sexual and reproductive health, adolescents, Uganda, developmental assets, developmental relationships

Peter C. Scales, PhD (the corresponding author) is a Senior Fellow at Search Institute, Minneapolis, MN. Mail: 940 Chestnut Ridge Road, Manchester, MO 63021. Email: scalespc@search-institute.org

Maura Shramko, MPP is a Doctoral candidate at the University of Arizona in the Department of Family Studies and Human Development, Tucson, AZ, and at the time of writing was a Research Associate at Search Institute, Minneapolis, MN. E-mail: mshramko@email.arizona.edu

Kim Ashburn, PhD is a Senior Research Officer at the Institute for Reproductive Health, Georgetown University, Washington, DC. E-mail: kaa22@georgetown.edu 
Early adolescence, from ages 10 to 14, is a critical transition period in young people's lives. During this period, the influence of broader ecological contexts (e.g., family, schools, neighborhoods) can lessen or heighten exposure to risk-taking behavior, and interventions that strengthen both individual and social assets in those contexts can be especially effective. Yet, the age group is "relatively neglected," overlooked by many international adolescent health programs (Igras, Macieira, Murphy, \& Lundgren, 2014; World Health Organization, 2010). The evidence base for supporting adolescent sexual and reproductive health (SRH) programs internationally tends to focus on 15- to 19-year-olds, and narrowly on standard demographic SRH data, or family planning services (Chong, Hallman, \& Brady, 2006; Save the Children and Women's Refugee Commission, 2012; Sommer, 2011; WHO, 2010). Many of these previous studies fail to capture factors in the wider context of adolescents' lives, such as gender norms and family support, that also influence SRH and behavior, particularly among very young adolescents, aged 10 to 14 . There is little research that explores very young adolescents' knowledge and awareness of their physical changes during puberty, their rights and responsibilities, or the effect of gender norms. Even less focus is given to their self-efficacy, commitment to learning, social competencies, and other developmental assets, or the relationship of those assets to their SRH. In the context of HIV, unwanted pregnancy, and other risks to SRH, it is coming to be recognized that a broader context that names "social” and "human" assets (e.g., social networks, trusting relationships, self-esteem, control over decisions) is important in addressing SRH challenges (Amin et al., 2013; Amin \& Chandra-Mouli, 2014; Blum, Astone, Decker, \& Chandra-Mouli, 2014; Erulkar, 2014; Svanemyr, Amin, Robles, \& Green, 2015). Thus, particularly in lower- and middle-income countries, research on adolescent SRH is urgently needed that further clarifies the broader developmental contexts young adolescents experience, and which help shape their SRH outcomes. Research that is more ecologically oriented can broaden potentially valid intervention targets and so increase program effectiveness.

\section{Present Investigation}

The current study addresses these gaps by examining the internal strengths and ecological contexts of support that very young adolescents experience in northern Uganda, and how these are related to SRH variables. By examining the role of social contexts, the study also brings to attention gender-based differences in social norms (e.g., acceptance of violence against women) that are critical environmental influences on the SRH decisions young people make. We hypothesized that youth with higher levels of internal strengths and ecological supports (developmental assets, defined further below), would report better SRH outcomes.

By accenting broader social contexts and gender issues, this study is relevant to adolescent SRH in developing countries in general, and for sub-Saharan Africa and Uganda in particular. Throughout sub-Saharan Africa, girls face disproportionate SRH risks relative to boys, including gender disparities in HIV/AIDS prevalence, girls being more likely to engage in high-risk sex (having had sex before age 15, or multiple partners, or last partner was casual), and the interconnected issues of child marriage and childbearing. At the same time, girls in sub-Saharan Africa, and younger girls especially, have fewer social assets than boys (reliable peer networks, safe spaces in the community to gather and meet friends, and access to media and messaging). These lower levels of social capital appear to be linked to risky sex, forced sex, and lower levels of HIV prevention (Amin et al., 2013). 
Nearly half of Uganda's population is under 15, and nearly one-quarter (23\%) of young females have their first intercourse by age 15 (Uganda Ministry of Health, 2004). Although statistics are not available for ages 10 to14, HIV/AIDS among women aged 15 to 29 is the leading cause of death in sub-Saharan Africa, accounting for $58 \%$ of all deaths in that age group (Lloyd, 2006). In Uganda, only 19\% of females aged 15 to19, and 42\% of males in that age group report using any form of modern contraception, including condoms, regardless of whether the intercourse takes places inside or outside or marriage. One result of this pattern is that young women are four times more likely than young men to be infected with HIV (Croce-Galis, 2005). Social norms in Uganda also continue to perpetuate genderbased violence against women, which exacerbates and contributes to the other risks to young women's SRH in Uganda (Mulumba, 2011; Naker, 2005). Investigating how individual and social assets may promote better SRH outcomes is potentially significant for promoting positive youth development and gender equality, both in Uganda and elsewhere.

\section{Theoretical and Research Background on Developmental Assets}

In this study, we use developmental assets as a measure of individual and social assets. The assets framework is situated within the broader field of Positive Youth Development (PYD), that is defined by an ecological (not only intra-individual) perspective (e.g., Bronfenbrenner \& Morris, 1998), and by focusing on the strengths in youths' lives (not only on their deficits) (e.g., Damon, 2004; Lerner, Brentano, Dowling, \&Anderson, 2002). Within PYD, a number of frameworks have gained both scholarly and applied traction in recent years, naming and measuring elements of person and context that promote positive growth. These include the risk and protective factors approach (Catalano, Berglund, Ryan, Lonczak, \& Hawkins, 2004); the 5 Cs - confidence, competence, character, caring, and connection (Pittman, Irby, \& Ferber, 2001; which Lerner et al., 2005, defined as leading to a sixth C, contribution); the five "promises" of the America's Promise Alliance (2006); the personal and social assets framework of the National Research Council (Eccles \& Gootman, 2002); and the developmental assets framework of Search Institute (Benson, Leffert, Scales, $\&$ Blyth, 1998). The assets framework has become the most frequently-cited PYD approach in the literature and has been used in research, program development, and community mobilization in at least 60 countries worldwide (Benson, Scales, \& Syvertsen, 2011).

Broadly, the assets encompass developmental relationships, opportunities, values, skills, and self-perceptions that research shows are strongly related to children's and youths' well-being, including school grades, positive emotions, and levels of purpose, violence, and civic engagement (Benson et al., 1998; see also Benson, Scales, Hamilton, \& Sesma, 2006; Pekel, Roehlkepartain, Syvertsen, \& Scales, 2015; Scales, Benson, Leffert, \& Blyth, 2000). Research with youth and young adults from developing and conflict or post-conflict countries, such as a USAID-funded study in Bangladesh, Honduras, Jordan, and Rwanda (Scales, Roehlkepartain, \& Fraher, 2012), has found that higher levels of developmental assets are associated with better outcomes in the areas of workforce development, education, health (including accurate HIV knowledge), conflict mitigation, and civic engagement. The effect sizes of these associations are substantial, ranging from medium to high.

Similar results have been found by other researchers utilizing different PYD measures similar to the developmental assets. For example, the more protective factors youth have, such as bonding to school, the better they are in virtually all outcomes studied (Catalano et al., 2004). Similarly, America's Promise Alliance (2006) reports that the higher young people score on measures of five asset-like variables (the five promises), such as having caring 
adults and opportunities to make a difference, the more positive their academic, psychological, social-emotional, and behavioral outcomes.

Social assets include the areas of Support, Empowerment, Boundaries \& Expectations, and Constructive Use of Time; individual assets encompass Commitment to Learning, Positive Values, Social Competencies, and Positive Identity, as shown in Table 1. The assets framework captures the individual level as well as the broader ecological, relational contexts of young people's lives (e.g., social or peers, family, school, community). This conceptualization allows for a holistic understanding of child and youth well-being, and is unique in its comprehensiveness. In a review of 244 studies of adolescent SRH in developing countries, Mmari and Sabherwal (2013) found that most risk and protective factors studied were focused on the individual, and that only in the last 10 years have family influences been emphasized as well. Those researchers concluded that the school, community, and neighborhood level has largely been ignored in such studies, a conclusion echoed by Amin et al. (2013). The assets framework used in the current study measures developmental relationships and opportunities at the school, community, and neighborhood level that have been overlooked in previous international SRH research, as well as the individual and family variables more commonly included. Thus, it is conceptually more wide-ranging and has more relevance to broader evidence-based positive youth development than any other approach to studying adolescent SRH in developing countries.

Previous research with U.S. samples of adolescents aged 12 to 18 has yielded two key findings relevant to the current study. First, the more developmental assets youth have, the less likely they are to engage in sexual intercourse, or to do so without contraception (Benson, Scales, Roehlkepartain, \& Leffert, 2011). Second, specific assets help promote positive adolescent SRH outcomes. For example, three assets - restraint, positive peer influence, and time at home - predict 19\% of adolescent sexual intercourse (Leffert et al., 1998).

Kirby, Laris, and Rolleri (2007) undertook a rigorous review of 83 studies of curriculum-based sex and HIV education programs using quasi-experimental or experimental designs. Their review included 18 studies from developing countries (including Kenya, Namibia, South Africa, Tanzania, and Zambia), with the curricula focusing on individual assets such as planning and decision making, and resistance skills. Two-thirds of programs reviewed had strong effects on preventing high-risk sexual behavior or promoting HIV and pregnancy prevention among youth (Kirby et al., 2007). Yet, the linkages of broader developmental assets and SRH outcomes for young adolescents have not been well-explored in non-U.S. samples. For example, a Save the Children girls' empowerment program for young rural girls in Bangladesh was found to increase developmental assets by an average of $22 \%$ across two years of program cohorts (Scales et al., 2013). However, the program did not include other outcome measures to link with the change in assets.

In contrast, the research results we report here serve to: (a) identify developmental assets that can be used to evaluate adolescent health programs, and that may have special relevance for reducing gender disparities in SRH in developing countries; and (b) provide program and policy implications for improving the well-being of young people, such as providing greater social support for both boys and girls. 


\section{Method}

The study used a cross-sectional design to measure the relation of developmental assets to adolescent SRH, consisting of a one-time administration of a 30-45 minute survey, which contained questions on developmental assets and adolescent SRH attitudes and behaviors. The survey was given to girls and boys aged 10 to14 years in Gulu district in the Northern region of Uganda. The region was selected because of the ongoing activities of the research team and in-country partners in this area. Approval was received from the office of the District Education Officer, Municipal Education Officer, and the Uganda National Council for Science and Technology Institutional Review Board (IRB). A smaller pilot study of 128 youths in the same age group was undertaken to validate the instrument in this population and test survey administration procedures.

Interviewers (12 male and 12 female) were from northern Uganda. All were fluent in English and Luo, and had extensive knowledge of the social, cultural, and political context in the region. The interviewers also had particular expertise in working with very young adolescents, as well as training in social work, counseling, and psychology. All interviewers received instruction by trained research staff in research ethics, protecting human subjects, and child protection, as well as study objectives, the data collection instrument, and administration procedures.

The team worked with bilingual interviewers (English and Luo) to translate the Search Institute’s Developmental Assets Profile (DAP) survey. A bilingual Luo language expert in Uganda who did not participate in the original English to Luo translation prepared a back translation. Final versions of all tools, in English and in Luo, received IRB approval before final study implementation.

\section{Sample Recruitment}

Gulu district education officials provided a list of primary and secondary schools, which were the sampling frame for selection of schools and students for inclusion in the survey. Schools were stratified by type of school, primary and secondary, and rural and semiurban location. Within each stratum, schools were randomly selected to obtain a sample representative of the student population. Interviewers then contacted the school principals to explain the purpose of the study and to request permission to recruit students. Within each selected school, individual classrooms containing students in the desired age group were systematically selected. Study interviewers visited the selected classrooms to explain the study and invite students to participate. Students were given participation cards that allowed them to indicate whether they were interested in participating by circling "yes" or "no". Interviewers left the classroom while students completed the participation cards to minimize any pressure to participate the students may have felt. All participation cards were collected by the teacher. By using the cards neither the teacher nor other students knew who wished to participate and who did not. Those students who expressed an interest in participating provided informed consent to the interviewer. 
All students in the selected classrooms who met eligibility criteria were selected until the desired sample size of about 1,000 students was achieved. ${ }^{1}$ In collaboration with school administration and teachers, informational events for parents were organized, and all parents of students in selected classrooms were invited. The parent events provided oral and written explanation of the study - its purpose, risks, and benefits. After participation in the event, parents were asked to indicate via consent form whether they would allow their child to participate. Only students whose parents so consented were invited to participate.

No youth declined participation, nor did any parents. However, a small number of parents (fewer than 10\%) did not return signed consent forms by the deadline, and as a result those few youth did not participate. All the students appeared keenly interested and excited to participate in the survey. It is difficult to say whether any student felt pressure, perhaps from their peers, to join the study, but the research team was very careful to emphasize that students were free to decline participation and that there would be no negative consequences for doing so.

\section{Sample Characteristics}

A total of 941 girls and boys aged 10 to 14 were administered the Luo DAP and SRH items. No surveys were lost due to data cleaning. The young adolescents came from 14 primary and secondary schools in northern Uganda. The final sample included $12 \%$ age 10 , $15 \%$ age $11,20 \%$ age $12,29 \%$ age 13 , and $24 \%$ age 14 . By grades, $84 \%$ were in primary school, and $16 \%$ in secondary. The sample comprised 52\% females and $48 \%$ males. A majority reported their religion as Catholic (69\%), and the great majority reported their tribe as Acholi (90\%).

A substantial majority of the children's families were struggling financially. More than a third of these 10- to14-year-old youth (36\%) reported that their families had difficulty affording even basic necessities, and another $40 \%$ said that they could manage the necessities but no more. About 20\% said that their families could sometimes afford to make special purchases, while just 3\% said that they could buy whatever they wished.

Families in the Northern region of Uganda are primarily of the Acholi ethnic group. Traditionally farmers and livestock herders, Acholi families live in compounds composed of small homes housing parents and immediate family members, sons and their wives, grandparents and aunts and uncles, children and grandchildren. Few in rural areas have formal employment. During the protracted 23-year civil war ending in 2008, communities in the region were heavily affected by violence and unrest. Nearly 2 million people were displaced into camps during the height of the conflict, including about $90 \%$ of the Acholi people (Gelsdorf, Maxwell, \& Mazurana, 2012). The war deeply affected social relationships, leaving many without the support of parents or elders to guide or provide for them. This likely has an effect on young parents who have limited role models for parenting young children. According to one report citing analysis of the Uganda Demographic and Health Survey (UDHS) 2010 data, "youth in the North are the poorest in the country with the lowest rates of education; the highest student-to-teacher ratios; the worst access to schools; the

\footnotetext{
${ }^{1}$ For $80 \%$ power with an alpha of .05 and an estimated effect size of .20, a total sample size of 788 was needed (per calculators at www.danielsoper.com/statcalc3/calc) if we wanted to compare two groups (by asset level, boys with girls, etc.). We then also added margin for loss of surveys due to data cleaning over incomplete surveys, suspicious response patterns, and so forth, a concern that was especially key given the young age of the participants.
} 
lowest percentages in wage employment; and the lowest rates of skills training" (International Youth Foundation, 2011, p. 52). Approximately 33\% of households are headed by females in the Northern region of Uganda.

\section{Measures}

The measure of developmental assets was Search Institute's Developmental Assets Profile (DAP) survey. The DAP is a 58-item survey in which youths report their experience of individual and social assets across the multiple ecological contexts of their lives. The survey was originally designed for young people aged 11 to 18 . It has been administered to more than 600,000 youths and young adults in the United States and internationally since its development in 2004. All DAP items are answered on the following scale: Not At All or Rarely (0 points), Somewhat or Sometimes (1 point), Very or Often (2 points), Extremely or Almost Always (3 points). Each scale can thus have a mean ranging from 0 to 3, and scale scores from 0 to 30 are obtained by then multiplying the mean score by 10 . The total DAP score is the total level of assets experienced by young people, encompassing both the individual and social assets. Scores range from 0 to 60 and are derived by adding the score for individual assets (0-30) to the score for social or ecological assets (0-30). The total DAP score is the most widely used measure of individual and social assets in the world, and has been found to be reliable and valid among both American youth (Search Institute, 2005), and among samples of youth from more than two dozen other countries in North America, South America, Europe, Africa, the Middle East, and Asia (Scales, 2011; Scales et al., 2013; Scales et al., 2012). In the current study, the total DAP score had an alpha reliability of 0.94 . Twelve of the 15 subscales had alphas $\geq 0.70$. Only the total DAP score was used in the current analysis. For some analyses, youths are divided into four levels signifying better or worse experience of developmental assets. Youths with scores from 0 to 29 are considered to be Very Vulnerable, from 30 to 41 Vulnerable, from 42 to 51 Adequate, and from 52 to 60 Good.

Measures of adolescent SRH included constructs such as knowledge of puberty, pregnancy risk, and HIV; communication with parents and other trusted adults, peers, and siblings about puberty and physical changes during adolescence, and about HIV and other sexually transmitted infections; health care access; and puberty-related gender norms. Measures were drawn from (a) previous Institute for Reproductive Health (IRH) measures used in Uganda; (b) previous measures developed for a USAID-funded study of developmental assets among youths and young adults in Bangladesh, Honduras, Jordan, and Rwanda (Scales et al., 2012); and (c) measures created for this study. The SRH measures were either single-item scales, or were intended to be indexes rather than unidimensional scales; thus, internal consistency reliability is not a meaningful indication of their quality (see Scales et al., 2008 for more). Table 1 provides sample items from the DAP and SRH measures. 
International Journal of Child, Youth and Family Studies (2016) 7(1): 45-64

Table 1

Sample Items by Scale

\begin{tabular}{cc}
\hline Scale & Sample Item \\
\hline
\end{tabular}

Developmental Assets Profile (DAP) ${ }^{\mathrm{a}}$

Support

Empowerment

Boundaries \& Expectations

Constructive Use of Time

Commitment to Learning

Positive Values

Social Competencies

Positive Identity

Accurate knowledge about puberty

Accurate knowledge about pregnancy risk

Accurate knowledge of HIV risk

Condom exposure and knowledge

Ability to access SRH

services

Supportive relationships:

Girls Only

Supportive relationships:

Boys Only

Equitable Gender Attitudes

Intended sexual behavior
I seek advice from my parents; I have a family that gives me love and support.

I feel valued and appreciated by others; I am given useful roles and responsibilities.

I have adults who are good role models for me; I have a family that knows where I am and what I am doing.

I am involved in creative things such as music, theater, or art; I am spending quality time at home with my parents

I enjoy reading or being read to; I have teachers who urge me to develop and achieve.

I am developing respect for other people; I tell the truth even when it is not easy.

I am sensitive to the needs and feelings of others; I plan ahead and make good choices.

I feel in control of my life and future; I am developing a sense of purpose in my life.

\section{SRH Measures ${ }^{\mathrm{b}}$}

Boys have their first ejaculation between the ages of 10 and 14.

Can a boy get a girl pregnant on any day of her menstrual cycle?

Can people get HIV/AIDS from mosquito bites?

Agree or disagree: A condom can prevent pregnancy.

I know where to go to get an HIV test.

In the last 3 months, have you talked to anyone about how to take care of yourself during your period?

During the last 3 months, have you talked to someone about how to take care of yourself once you start having wet dreams?

It is equally important for girls to go to school as it is for boys.

If you ever have sex before marriage, would you use a condom?

\footnotetext{
${ }^{a}$ Answered on 4-point response scale: Not At All or Rarely, Somewhat or Sometimes, Very or Often, Extremely or Almost Always

${ }^{\mathrm{b}}$ Most answered on a strongly agree-strongly disagree scale. Some yes-no.
} 


\section{Results}

\section{Extent of Experiencing Developmental Assets}

Figure 1 shows that a majority of youth in this sample (61\%) reported "Adequate" or "Good" levels of developmental assets. Nevertheless, the mean total DAP was just 44.43 out of a possible 60, interpreted as barely “Adequate.” Means for the other scales (not shown) also suggest that these Ugandan youth have a barely acceptable level of developmental relationships, opportunities, and internal strengths in their lives, with higher levels in their families and schools, and in their positive attitudes about learning.

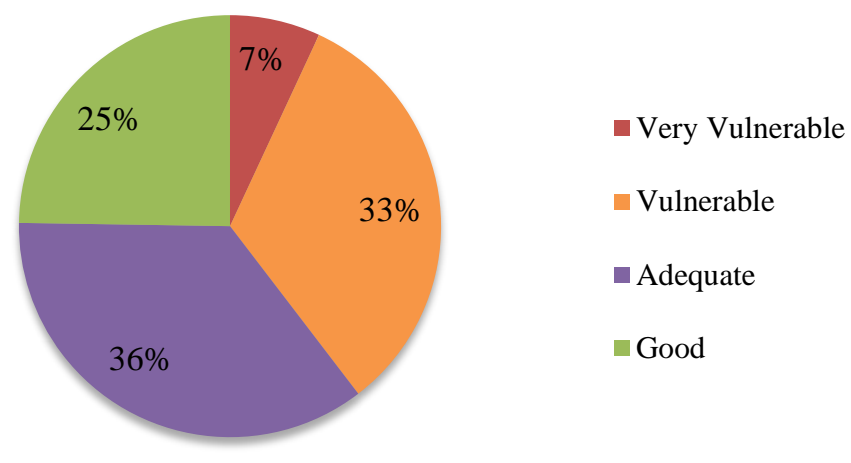

Figure 1. Percentage of Northern Uganda young adolescents (10-14 year olds), by total DAP score quartile, $\mathrm{n}=941$.

\section{Extent of Experiencing Concurrent Sexual and Reproductive Health Outcomes}

In terms of pubertal development, this sample was in the early stages. Just $33 \%$ of girls said they had had their first period, and only $20 \%$ of boys had had a nocturnal emission or wet dream. A slight majority of the girls, 55\%, said they could manage the issues around having their periods, but only 37\% of boys who had had wet dreams said they understood what was happening. Nearly one in five girls who had had their period (19\%) said they had missed three or more days of school as a result. Most of these youths did not talk with anyone about these experiences.

For the SRH indicators, binary scoring (a youth "has" or "does not have" the outcome) was used instead of continuous scoring (means) to report the prevalence of these indicators. Binary scoring was used for two reasons. First, the multi-item SRH measures were not intended to function as scales, but as indices. Means for groups of items that are not meant to be scales do not have the same meaning as measures of central tendency derived from groups of items that do have adequate internal consistency and "hang together" as scales. Also, some of the SRH measures were single items only, whose means would not then be based on as much information as the means from multi-item measures. Second, differing response options were used for different measures, both multi-item and single item measures. Thus, means on the raw responses could not properly be compared with each other. Standardized means were used in some analyses, such as analyses of variance, to enable comparing results on measures with differing response options. But standardized means, by 
definition having a mean of 0 and a standard deviation of 1 , cannot communicate the prevalence of an indicator in units that are meaningful for that indicator. For these reasons, binary scoring was used.

The cutoffs to determine whether a youth had or did not have a SR indicator were based on scoring algorithms developed by Search Institute. In general, these cutoffs require a response on any response scale that is equivalent to averaging an "agree" on a 4-point "strongly agree" to "strongly disagree" scale, across the items that make up that measure. The validity of this approach has long been demonstrated, as these cutoff levels have been shown to significantly differentiate levels of youth well-being on numerous academic, socialemotional, psychological, and behavioral outcomes, across widely diverse samples (Benson, Scales, \& Syvertsen, 2011; Scales et al., 2008).

Table 2 shows the percentage of the sample that met the criteria for having the SRH outcomes. Of eight key SRH outcomes, young adolescents in this sample did not meet criterion levels for having two of them (accurate knowledge about pregnancy risk, and supportive relationships for both girls and boys). Moreover, only small to moderate majorities (57\%-65\%) meeting criterion levels were observed for five other outcomes (equitable gender attitudes, accurate knowledge about puberty, ability to access SRH services, condom exposure and knowledge, and intended sexual behavior). For the remaining SRH outcome, knowledge of HIV risk, 73\% met the criterion.

It is worth noting that $77 \%$ of the participants state that they will use a condom if they do have sex before marriage. This figure can be interpreted both positively, and with some concern. On the one hand, three in four of these very young adolescents say they intend to take a major step toward HIV prevention, by using a condom. On the other hand, nearly one in four did not express this intention, which suggests there is still work to do to increase the intended use of condoms and lower the risk of HIV infection.

Table 2 also shows the frequency of these outcomes by gender. Girls were better off than boys on most of the outcomes. 
Table 2

Percentage of Northern Uganda Young Adolescents with SRH Outcomes, Total and by Gender

\begin{tabular}{|c|c|c|c|c|}
\hline \multirow[t]{2}{*}{ SRH Outcome } & \multirow[t]{2}{*}{ Criteria for outcome } & \multicolumn{3}{|c|}{ Percent } \\
\hline & & $\begin{array}{c}\begin{array}{c}\text { Full sample, } \\
\mathrm{n}=941\end{array} \\
\end{array}$ & $\begin{array}{c}\text { Girls, } \\
\mathrm{n}=487\end{array}$ & $\begin{array}{l}\text { Boys, } \\
\mathrm{n}=454\end{array}$ \\
\hline $\begin{array}{l}\text { Accurate knowledge about } \\
\text { puberty }\end{array}$ & Correctly answers three of four knowledge questions & 62 & 72 & 51 \\
\hline $\begin{array}{l}\text { Accurate knowledge about } \\
\text { pregnancy risk }\end{array}$ & Correctly answers three of four knowledge questions & 47 & 51 & 33 \\
\hline $\begin{array}{l}\text { Accurate knowledge of } \mathrm{HIV} \\
\text { risk }\end{array}$ & $\begin{array}{l}\text { Answers false that HIV can be transmitted by mosquito } \\
\text { bite }\end{array}$ & 73 & 76 & 70 \\
\hline $\begin{array}{l}\text { Condom exposure and } \\
\text { knowledge }\end{array}$ & $\begin{array}{l}\text { Answers true to condom can prevent pregnancy, and can } \\
\text { prevent HIV }\end{array}$ & 65 & 62 & 68 \\
\hline $\begin{array}{l}\text { Ability to access SRH } \\
\text { services }\end{array}$ & $\begin{array}{l}\text { Answers four of five questions in the direction of agreeing } \\
\text { they can access various SRH services }\end{array}$ & 63 & 67 & 60 \\
\hline Supportive relationships & $\begin{array}{l}\text { Talks with adults and friends about changes in } \\
\text { adolescence, feelings, and romantic relationships }\end{array}$ & 24 & 24 & 12 \\
\hline Equitable Gender Attitudes & $\begin{array}{l}\text { Answers five of six attitude questions in the direction of } \\
\text { supporting equality between males and females }\end{array}$ & 57 & 65 & 49 \\
\hline Intended sexual behavior & $\begin{array}{l}\text { Expects to delay sex until marriage, and to use a condom } \\
\text { if having sex before marriage }\end{array}$ & 58 & 63 & 52 \\
\hline
\end{tabular}


International Journal of Child, Youth and Family Studies (2016) 7(1): 45-64

\section{Association between Developmental Assets and SRH Measures}

Due to limited empirical evidence linking personal and social assets with SRH outcomes for very young adolescents, we first looked at the correlations between the SRH outcomes and developmental assets, then conducted analyses of variance, and logistic regressions. All analyses converged on similar results, and so we report here only the logistic regressions.

Level of assets (the two highest levels, Adequate and Good) were used to predict having the SRH outcomes. The results in Table 3 show the odds of youth at the Adequate or Good level of assets having the SRH outcomes, as compared to youth at the Very Vulnerable or Vulnerable levels (column 2), and the odds of youth at the Good level having the outcomes, as compared to all other youth (column 3). ${ }^{\mathrm{b}}$

These results suggest considerable support for our hypothesis. Specifically, youth at the two highest asset levels are significantly more likely than youth at the lowest two levels to have three of the outcomes (accurate HIV knowledge, access to SRH services, and intended sexual behavior). In addition, youth at the highest asset level, Good, are significantly more likely than youth at all three of the other asset levels to have four of the outcomes (accurate HIV knowledge, accurate condom knowledge, supportive relationships for girls and boys, and intended sexual behavior).

The practical meaning of the results is more evident in these logistic regressions than in other kinds of analyses. For example, boys at the Good assets level have twice the odds of having supportive relationships as all other boys (ExpB of 2.02), and youth at least at the Adequate level of assets are 87\% more likely (ExpB of 1.87) to have accurate knowledge about HIV, and 98\% more likely (ExpB of 1.98) to have the intention to delay sex until marriage or to use a condom. Such differences can be expected to give rise to corresponding differences in the sexual and reproductive health of these adolescents.

Additional analyses (available from the authors) showed that the assets-SRH linkage was stronger and more pervasive for girls. For example, of 38 significant correlations between the eight asset categories and eight SRH outcomes, 14 were significant for both males and females, but 16 were significant for girls only (especially puberty knowledge, and confidence in accessing SRH services), compared with 8 significant for boys only. Commitment to Learning and Social Competencies were each significantly correlated with 7 of the 8 SRH outcomes.

\footnotetext{
$\mathrm{b}$ These are the unadjusted odds, not accounting for variables such as gender or age within the 10- to 14-year-old range.
} 
International Journal of Child, Youth and Family Studies (2016) 7(1): 45-64

Table 3

Odds of Uganda 10- to 14-Year-Olds Having Sexual and Reproductive Health Outcomes at Adequate or Thriving Levels of Developmental Assets

\begin{tabular}{|c|c|c|}
\hline & \multicolumn{2}{|c|}{ Assets Level: $\operatorname{ExpB}(\mathrm{p})^{\mathrm{a}}$} \\
\hline & Adequate-Thriving $^{\mathrm{b}}$ & Thriving $^{\mathrm{c}}$ \\
\hline $\begin{array}{l}\text { Accurate knowledge about } \\
\text { puberty }\end{array}$ & $1.30(.057 \mathrm{NS})$ & $1.24(.180 \mathrm{NS})$ \\
\hline $\begin{array}{l}\text { Accurate knowledge about } \\
\text { pregnancy risk }\end{array}$ & $0.93(.574 \mathrm{NS})$ & $1.01(.938 \mathrm{NS})$ \\
\hline Accurate knowledge of HIV & $1.71(.000)$ & $1.87(.001)$ \\
\hline Condom knowledge & $1.18(.293 N S)$ & $1.57(.012)$ \\
\hline $\begin{array}{l}\text { Ability to access SRH } \\
\text { services }\end{array}$ & $1.34(.035)$ & $1.27(.136 \mathrm{NS})$ \\
\hline \multicolumn{3}{|l|}{ Supportive relationships: } \\
\hline Girls ( $n=118$ have the & $1.41(.125 N S)$ & $1.78(.013)$ \\
\hline $\begin{array}{l}\text { outcome, versus } 369 \text { do not) } \\
\text { Boys ( } n=56 \text { have the } \\
\text { outcome, versus } 398 \text { do not) }\end{array}$ & $1.71(.081 \mathrm{NS})$ & $2.02(.019)$ \\
\hline Equitable gender attitudes & $0.81(.121 \mathrm{NS})$ & 0.78 (.106NS) \\
\hline Intended sexual behavior & $1.98(.000)$ & $1.75(.000)$ \\
\hline
\end{tabular}

${ }^{a}$ ExpB expresses the odds of youth having the outcome if they have either an Adequate or Thriving level of assets, or a Thriving level. For example, youth with either an Adequate or Thriving level of assets are $71 \%$ (an ExpB of 1.71) more likely than other youth to have accurate HIV knowledge, and youth at the Thriving level are 87\% more likely (ExpB of 1.87) to have accurate HIV knowledge than all other youth.

${ }^{b} \mathrm{~N}=510$ at the combined Adequate + Thriving levels, versus 373 combined Challenged + Vulnerable.

${ }^{\mathrm{c}} \mathrm{N}=232$ at the Thriving level, versus 711 combined at the Adequate, Vulnerable, and Challenged levels.

\section{Limitations}

Amin et al. (2013) note that the most vulnerable Ugandan girls typically are out of school and married. Our study involved unmarried girls in school, and so did not represent the most vulnerable youth. This sample's girls were relatively advantaged by being unmarried and in school, even though their gender alone in a developing country puts them in a disadvantaged class. Our participant age range of 10 to 14 covers Uganda grades P5 to P7. In P5, 63\% of girls are enrolled in school, but by P7, the number has dropped to just 32\% (UNICEF Uganda, 2015). Nevertheless, the relation of higher asset level to better concurrent SRH speaks to the potential value of building youths' developmental assets in reducing the vulnerability of young girls in Uganda, especially those girls who have been forced to marry early and leave school.

In addition, we measured concurrent and not prospective outcomes. This study's findings must be replicated in a longitudinal study for cause-effect conclusions to be drawn. 
However, they also are consistent with findings from an earlier study of developmental assets and youth well-being in developing or post-conflict countries. In that study, higher levels of assets (measured using the DAP survey used in the current study) were significantly correlated with various concurrent workforce development, education, health, violence prevention, and civic development outcomes among more than 3,000 older youths and young adults in Bangladesh, Honduras, Jordan, and Rwanda (Scales et al., 2012).

\section{Conclusion}

This study looked at the link between developmental assets - developmental relationships, opportunities, values, skills, and self-perceptions of youth — and sexual and reproductive health outcomes among very young adolescents in Uganda. We hypothesized that higher levels of developmental assets would be linked with better concurrent SRH outcomes.

The majority of the findings supported our hypothesis. We found that most youth did not meet or barely met cutoffs for having SRH outcomes. However, youth with higher levels of developmental relationships, opportunities, and internal strengths had more accurate knowledge about condoms, more accurate knowledge about HIV risk, more perceived ability to access SRH services, more supportive relationships in which they could talk about feelings and what happens during puberty, and lower intentions to engage in risky sexual behavior. In addition, girls were more likely than boys to have most of the SRH outcomes, with the exception of accurate knowledge of and exposure to condoms, where boys were slightly ahead.

These findings highlight the need to ensure programs are sensitive to the differential vulnerabilities of girls versus boys. For example, even in our relatively advantaged sample, in which both the girls and boys were in school, boys had more limited social support for talking about SRH issues, a difference that should be addressed. Promotion of developmental assets may be especially important to girls, being significantly related to their confidence in accessing SRH services, an association not found among the boys. Other strategies for interventions are also suggested by the data, such as:

- Working with parents to improve their ability to provide support for their children, and to respect, set, and monitor appropriate boundaries.

- Providing human rights-based programming that promotes community engagement and encourages youths to become involved in community service and action.

- Employing activities which provide youths with opportunities to learn and develop new skills.

- Establishing linkages with caring adults in schools, communities, and other institutions to increase social support for youths.

- Reinforcing policies that keep boys and especially girls in school, and enable them to learn social skills such as communication and refusal skills, because Commitment to Learning and Social Competencies were the most pervasively significant asset categories correlated with SRH outcomes. 
Developmental assets level was not linked to more equitable gender attitudes. Because the assets tap a variety of social competencies, including skills for avoiding risky situations, and positive values, such as equality and social justice, we anticipated that higher assets level might be linked to more equitable gender attitudes. The mixed results for equitable gender attitudes may be a result of ambiguous gender-related norms in Uganda, which do teach youth that girls' education is important, but still reinforce the idea that violence against girls is acceptable (Mulumba, 2011; Naker, 2005). Gender-based violence is common in northern Uganda (Uganda Bureau of Statistics and ICF International, 2012). Thus, even those very young adolescents with high levels of developmental assets live in a society that exhibits both rigid gender norms in general, and, specifically, socially-sanctioned norms of violence, making those norms especially hard to overcome.

Even though assets were not correlated with gender attitudes, there was a significant gender gap, with girls 35\% more likely to have equitable attitudes than boys. Although our data do not speak directly to this point, we concur with Igras et al. (2014) and WHO (2010) that broader contexts beyond the individual are crucial for significant change in gender norms to occur. It might be that even for youths with good levels of social assets from family, school, and community, more explicit discussion in all those contexts about dealing with and changing those negative gender norms will be necessary for transformation of those norms to occur. Special attention to helping boys' attitudes become more equitable is also suggested by our results.

Our study's most critical finding was that, for both girls and boys, higher levels of assets were related to greater intentions to abstain from intercourse and to use condoms when engaging in sexual activity. Developing valid SRH measures for very young adolescents is a challenge. Most either are not sexually active or are unwilling to admit being so; further, between ages 10 and 14, there are large variations in the biological and psychological determinants of SRH, and in life circumstances affecting SRH choices. The fact that higher levels of developmental assets were related to less risky sexual behavior intentions for both girls and boys at this young age suggests both the potential relevance of broader developmental assets to SRH programs, and that the assets may be a protective influence for both genders. In addition, higher assets were related to girls' (but not boys') greater confidence in accessing SRH services that can maintain their well-being. This suggests both that the survey content may have been especially salient to girls, and that building developmental relationships, opportunities, and internal strengths therefore might be a mechanism that helps reduce disparities in SRH that disproportionately affect young women in sub-Saharan Africa.

These results from Uganda are quite similar to the results of a large U.S. study of middle- and high-school students, showing as in our study that higher developmental assets levels were significantly associated with abstinence from sexual intercourse, and with use of contraception among those who did report having intercourse (Benson, Scales, Roehlkepartain, et al., 2011). The cross-cultural similarity of these associations suggests the robust validity of the connection between assets and less risky developmental paths of sexual and reproductive behavior. In the current study, the consistency of results underscores this connection. Higher assets levels were significantly correlated with greater knowledge of puberty, pregnancy risk, HIV risk, and confidence accessing SRH services. All of these are mechanisms that promote adolescent sexual and reproductive health. Moreover, odds ratios showed that these SRH differences by asset level were meaningful in terms of effect size. The size of these differences based on developmental assets level can translate into consequential differences in the SRH of these young adolescents. 
Thus, with a few exceptions (notably, the mixed findings for equitable gender attitudes, which can largely be explained by strong gender-linked norms in Uganda), the majority of our findings suggest a potential utility for promoting developmental relationships and opportunities for youth. The results also suggest the value of promoting positive commitments to learning and a variety of social competencies and values as an additional strategy for improving SRH among young adolescents in a developing country setting.

The robustness of these findings in cross-sectional correlational research suggests a likelihood of observing the same link with longitudinal research designs. USAID's youth development policy (U.S. Agency for International Development, 2012), in common with the U.K.'s Department of Foreign and International Development, WHO, and the United Nations Population Fund, calls for such investment in building youth's developmental assets - their developmental relationships and opportunities, and their internal values, skills, and selfperceptions - to be part of a broad strategy for promoting positive youth development in developing countries. Such a strategy could address a range of specific desired outcomes, in SRH and other domains. The current study's results offer additional evidence for the potential utility of such policies for promoting and enhancing young people’s well-being worldwide. 
International Journal of Child, Youth and Family Studies (2016) 7(1): 45-64

\section{References}

America's Promise Alliance. (2006). Every child, every promise: Turning failure into action. Alexandria, VA: Author.

Amin, S., Austrian, A., Chau, M., Glazer, K., Green, E., Stewart, D., \& Stoner, M. (2013). Adolescent Girls Vulnerability Index: Guiding strategic investment in Uganda. New York, NY: Population Council.

Amin, A., \& Chandra-Mouli, V. (2014) Starting young: Developing egalitarian gender norms and relations to promote sexual and reproductive health and rights of adolescents and adults. Entre Nous, 80, 201-21.

Benson, P. L., Leffert, N., Scales, P. C., \& Blyth, D. A. (1998). Beyond the 'village' rhetoric: Creating healthy communities for children and adolescents. Applied Developmental Science, 2(3), 138-159.

Benson, P. L., Scales, P. C., Hamilton, S. F., \& Sesma, A., Jr. (2006). Positive youth development: Theory, research, and applications. In W. Damon, \& R. M. Lerner (Eds.), Handbook of child psychology (6th ed., pp. 894-941). New York, NY: John Wiley.

Benson, P. L., Scales, P. C., Roehlkepartain, E. C., \& Leffert, N. (2011). A fragile foundation: The state of developmental assets among American youth. Minneapolis, MN: Search Institute.

Benson, P. L., Scales, P. C., \& Syvertsen, A. K. (2011). The contribution of the developmental assets framework to positive youth development theory and practice. In R. M. Lerner, J. V. Lerner, \& J. B. Benson (Eds.), Advances in child development and behavior: Positive youth development research and applications for promoting thriving in adolescence (pp. 198-232). London, UK: Elsevier.

Blum, R., Astone, N., Decker, M., \& Chandra-Mouli, V. (2014). A conceptual framework for early adolescence: A platform for research. International Journal of Adolescent Medicine and Health, 26(3), 321-331.

Bronfenbrenner, U., \& Morris, P. (1998). The ecology of developmental processes. In W. Damon \& R. M. Lerner (Eds.), Handbook of child psychology: Vol. 1. Theoretical models of human development (5th ed., pp. 993-1028). New York, NY: Wiley.

Catalano, R. F., Berglund, M. L., Ryan, J. A. M., Lonczak, H. S., \& Hawkins, J. D. (2004). Positive youth development in the United States: Research findings on evaluations of positive youth development programs. Annals of the American Academy of Political and Social Science, 591, 98-124.

Chong, E, Hallman, K, \& Brady, M. (2006) Investing when it counts. Generating the evidence base for policies and programmes for very young adolescents: Guide and tool kit. New York, NY: UNFPA.

Croce-Galis, M. (2005). Adolescents in Uganda: Sexual and reproductive health. (Research in Brief, No. 2). New York, NY: Alan Guttmacher Institute.

Damon, W. (2004). What is positive youth development? Annals of the American Academy of Political and Social Science, 591, 13-24. 
International Journal of Child, Youth and Family Studies (2016) 7(1): 45-64

Eccles, J., \& Gootman, J. A. (2002). Community programs to promote youth development: Committee on community-level programs for youth (National Research Council and Institute of Medicine. Division of Behavioral and Social Sciences and Education, Board on Children, Youth and Families). Washington, DC: National Academy Press.

Erulkar, A. (2014). Building the assets to thrive: Addressing the HIV-related vulnerabilities of adolescent girls in Ethiopia. Washington, DC: Population Council.

Gelsdorf, K., Maxwell, D., \& Mazurana, D. (2012). Livelihoods, basic services, and social protection in Northern Uganda and Karamoja. London, UK: Secure Livelihoods Research Consortium.

Igras, S. M., Macieira, M., Murphy, E., \& Lundgren, R. (2014). Investing in very young adolescents’ sexual and reproductive health. Global Public Health, 9(5), 555-569.

International Youth Foundation. (2011). YouthMap Uganda: Navigating challenges. Charting Hope. A cross-sector situational analysis on youth in Uganda. Baltimore, MD: Author.

Kirby, D. B., Laris, B. A., \& Rolleri, L. A. (2007). Sex and HIV education programs: Their impact on sexual behaviors of young people throughout the world. Journal of Adolescent Health, 40, 206-217.

Leffert, N., Benson, P. L., Scales, P. C., Sharma, A., Drake, D., \& Blyth, D. A. (1998). Developmental assets: Measurement and prediction of risk behaviors among adolescents. Applied Developmental Science, 2(4), 209-230.

Lerner, R. M., Brentano, C., Dowling, E. M., \& Anderson, P. M. (2002). Positive youth development: Thriving as the basis of personhood and civil society. New Directions for Youth Development: Pathways to Positive Development Among Diverse Youth, 95, 1133.

Lerner, R. M., Lerner, J. V., Alermigi, J., Theokas, C., Phelps, E., Gestsdottir, S., „,, von Eye, A. (2005). Positive youth development, participation in community youth development programs, and community contributions of fifth grade adolescents: Findings from the first wave of the 4-H Study of positive youth development. Journal of Early Adolescence, 25, 17-71.

Lloyd, C. B. (2006). Schooling and adolescent reproductive behavior in developing countries. New York, NY: United Nations Millennium Project.

Mmari, K., \& Sabherwal, S. (2013). A review of risk and protective factors for adolescent sexual and reproductive health in developing countries: An update. Journal of Adolescent Health, 53(5), 562-572.

Mulumba, D. (2011). Encampment of communities in war-affected areas and its effects on their livelihood security and reproductive health: The case of Northern Uganda. Eastern Africa Social Science Research Review, 27 (1), 107-129.

Naker, D. (2005). Violence against children: The voices of Ugandan children and adults. Kampala, Uganda: Raising Voices. 
International Journal of Child, Youth and Family Studies (2016) 7(1): 45-64

Pekel, K., Roehlkepartain, E. C., Syvertsen, A. K., \& Scales, P. C. (2015). Don't forget the families: The missing piece in America's effort to help all children succeed. Minneapolis, MN: Search Institute.

Pittman, K., Irby, M., \& Ferber, T. (2001). Unfinished business: Further reflections on a decade of promoting youth development. In P. L. Benson \& K. J. Pittman (Eds.), Trends in youth development: Visions, realities and challenges (pp. 3-50). Boston, MA: Kluwer Academic.

Save the Children and Women's Refugee Commission. (2012). Adolescent sexual and reproductive health in humanitarian settings: An in-depth look at family planning services. Washington, DC: Author.

Scales, P. C. (2011). Youth developmental assets in global perspective: Results from international adaptations of the Developmental Assets Profile. Child Indicators Research, 4, 619-645. Advance online publication. doi: 10.1007/s12187-011-9112-8

Scales, P. C., Benson, P. L., Dershem, L., Fraher, K., Makkonen, R., Nazneen, S., ... Titus, S. (2013). Building developmental assets to empower adolescent girls in rural Bangladesh: Evaluation of Project Kishoree Kontha [Special issue]. Journal of Research on Adolescence , 23(1), 171-184.

Scales, P. C., Benson, P. L., Leffert, N., \& Blyth, D.A. (2000). Contribution of developmental assets to the prediction of thriving among adolescents. Applied Developmental Science, 4(1), 27-46.

Scales, P. C., Benson, P. L., Moore, K. A., Lippman, L., Brown, B., \& Zaff, J. F. (2008). Promoting equal developmental opportunity and outcomes among America's children and youth: Results from the National Promises Study. Journal of Primary Prevention, 29 (2), 121-144.

Scales, P. C., Roehlkepartain, E. C., \& Fraher, K. (2012). Do developmental assets make a difference in majority-world contexts? A preliminary study of the relationships between developmental assets and international development priorities [Final Report to United States Agency for International Development and Education Development Center]. Minneapolis, MN: Search Institute.

Search Institute. (2005). Developmental Assets Profile: User manual. Minneapolis, MN: Author.

Sommer, M. (2011) An overlooked priority: Puberty in sub-Saharan Africa. American Journal of Public Health, 101(6), 979-981. doi:10.2105/AJPH.2010.300092

Svanemyr, J., Amin, A., Robles, O. J., \& Greene, M. E. (2015). Creating an enabling environment for adolescent sexual and reproductive health: A framework for promising approaches. Journal of Adolescent Health, 56, S7-S14.

Uganda Bureau of Statistics (UBOS) and ICF International Inc. (2012). Uganda demographic and health survey 2011. Kampala, Uganda: UBOS and Calverton, MD: ICF International.

Uganda Ministry of Health. (2004). National adolescent health policy in Uganda. Kampala, Uganda: Ministry of Health, Reproductive Health Division. 
International Journal of Child, Youth and Family Studies (2016) 7(1): 45-64

UNICEF Uganda. (2015). Situation analysis of children in Uganda 2015. Kampala, Uganda: Ministry of Gender, Labour, and Social Development, and UNICEF Uganda.

U.S. Agency for International Development. (2012). Youth in development: Realizing the demographic opportunity. Washington, DC: USAID.

World Health Organization. (2010). The sexual and reproductive health of young adolescents in developing countries: Reviewing the evidence, identifying research gaps, and moving the agenda. Report of a WHO Technical Consultation, Geneva, November 4-5, 2010. Geneva, Switzerland. 